\title{
ACUTE AEROBIC EXERCISE REDUCES 24-H AMBULATORY BLOOD PRESSURE LEVELS IN LONG- TERM-TREATED HYPERTENSIVE PATIENTS
}

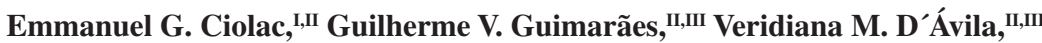 \\ Luiz A. Bortolotto, III Egídio L. Doria, ${ }^{\text {IV }}$ Edimar A. BocchiIIIII
}

doi: 10.1590/S1807-59322008000600008

Ciolac EG, Guimarães GV, D’Ávila VM, Bortolotto LA, Doria EL, Bocchi EA. Acute aerobic exercise reduces 24-h ambulatory blood pressure levels in long-term-treated hypertensive patients. Clinics. 2008;63:753-8.

BACKGROUND: Even with anti-hypertensive therapy, it is difficult to maintain optimal systemic blood pressure values in hypertensive patients. Exercise may reduce blood pressure in untreated hypertensive, but its effect when combined with long-term anti-hypertensive therapy remains unclear. Our purpose was to evaluate the acute effects of a single session of aerobic exercise on the blood pressure of long-term-treated hypertensive patients.

METHODS: Fifty treated hypertensive patients (18/32 male/female; $46.5 \pm 8.2$ years; Body mass index: $\left.27.8 \pm 4.7 \mathrm{~kg} / \mathrm{m}^{2}\right) \mathrm{were}$ monitored for $24 \mathrm{~h}$ with respect to ambulatory (A) blood pressure after an aerobic exercise session (post-exercise) and a control period (control) in random order. Aerobic exercise consisted of 40 minutes on a cycle-ergometer, with the mean exercise intensity at $60 \%$ of the patient's reserve heart rate.

RESULTS: Post-exercise ambulatory blood pressure was reduced for $24 \mathrm{~h}$ systolic $(126 \pm 8.6 \mathrm{vs} .123 .1 \pm 8.7 \mathrm{mmHg}$, p=0.004) and diastolic blood pressure $(81.9 \pm 8$ vs. $79.8 \pm 8.5 \mathrm{mmHg}, \mathrm{p}=0.004)$, daytime diastolic blood pressure $(85.5 \pm 8.5 \mathrm{vs} .83 .9 \pm 8.8 \mathrm{mmHg}$, $\mathrm{p}=0.04)$, and nighttime $\mathrm{S}(116.8 \pm 9.9$ vs. $112.5 \pm 9.2 \mathrm{mmHg}, \mathrm{p}<0.001)$ and diastolic blood pressure $(73.5 \pm 8.8 \mathrm{vs} .70 .1 \pm 8.4 \mathrm{mmHg}$, $\mathrm{p}<0.001)$. Post-exercise daytime systolic blood pressure also tended to be reduced (129.8 $\pm 9.3 \mathrm{vs} .127 .8 \pm 9.4 \mathrm{mmHg}$, $\mathrm{p}=0.06)$. These post-exercise decreases in ambulatory blood pressure increased the percentage of patients displaying normal $24 \mathrm{~h}$ systolic blood pressure $(58 \%$ vs. $76 \%, \mathrm{p}=0.007)$, daytime systolic blood pressure $(68 \%$ vs. $82 \%, \mathrm{p}=0.02)$, and nighttime diastolic blood pressure ( $56 \%$ vs. $72 \%, \mathrm{p}=0.02$ ). Nighttime systolic blood pressure also tended to increase ( $58 \%$ vs. $80 \%, \mathrm{p}=0.058)$.

CONCLUSION: A single bout of aerobic exercise reduced $24 \mathrm{~h}$ ambulatory blood pressure levels in long-term-treated hypertensive patients and increased the percentage of patients reaching normal ambulatory blood pressure values. These effects suggest that aerobic exercise may have a potential role in blood pressure management of long-term-treated hypertensive.

KEYWORDS: Hypertension; Exercise; Blood Pressure; Treated Hypertension.

\section{INTRODUCTION}

Systemic arterial hypertension is a highly prevalent

\footnotetext{
${ }^{\mathrm{I}}$ Laboratory of Kinesiology, Institute of Orthopedics and Traumatology, Hospital das Clínicas, Faculdade de Medicina, Universidade de São Paulo - São Paulo/SP, Brazil.

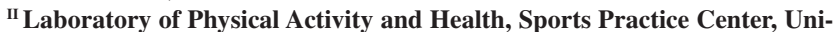
versidade de São Paulo - São Paulo/SP, Brazil.

IIIHeart Institute, Hospital das Clínicas, Faculdade de Medicina, Universidade de São Paulo - São Paulo/SP, Brazil.

${ }^{\text {Iv }}$ Hospital Universitário, Universidade de São Paulo - São Paulo/SP, Brazil. Email: egciolac@hcnet.usp.br

Tel.: 55113069.6041

Received for publication on April 28, 2008

Accepted for publication on August 20, 2008
}

disease, ${ }^{1,2}$ affecting approximately one billion individuals worldwide, and is a major risk factor associated with increased all-cause and cardiovascular mortality. ${ }^{2}$ Cardiovascular risk is dependent on systemic arterial blood pressure (BP), with optimal values below 120/80 $\mathrm{mmHg}{ }^{2,3}$ Systemic arterial hypertension treatments include lifestyle modifications and pharmacological interventions. ${ }^{2}$ However, major pharmacological trials have demonstrated that maintaining BP at normal levels is difficult, ${ }^{4}$ with only 25 to $62 \%$ of patients being properly controlled. ${ }^{4-6}$

Among lifestyle modifications, physical activity is important because it has been associated with a lower incidence of hypertension in different populations. ${ }^{7-9}$ Additionally, physical activity reduces the $\mathrm{BP}$ of hypertensive 
and normotensive subjects, ${ }^{10}$ with greater and longer-lasting reductions observed in subjects with higher BP levels. ${ }^{14}$ Several studies have shown that just a single set of dynamic exercise can decrease BP to below basal levels in hypertensive subjects and that this hypotensive effect remains for several hours after exercise. ${ }^{11-14}$ This acute exercise-mediated BP reduction is clinically significant. ${ }^{14}$ However, post-exercise BP reduction has only been reported in uncontrolled hypertensive patients not taking medication; therefore, it is necessary to investigate whether this effect also occurs in long-term-treated hypertensive patients taking anti-hypertensive medications.

Thus, the goal of the present study was to evaluate the effect of a single bout of aerobic exercise on BP in patients receiving long-term anti-hypertensive treatment.

\section{METHODS}

\section{Study Design}

All volunteers were selected from the hypertension group at the University Hospital of the University of Sao Paulo. They underwent clinical evaluation and maximal graded exercise testing. Two 24 hour ( $24 \mathrm{~h}$ ) ambulatory BP (ABP) monitoring were performed after a session of aerobic exercise (post-exercise) and after a nonexercise control period (control). The local ethics committee approved all procedures. The volunteers read a detailed description of the protocol and provided written informed consent.

\section{Population}

Middle-aged hypertensive volunteers receiving treatment for arterial hypertension for $9.4 \pm 6.1$ years, with office $\mathrm{BP}<140 / 90 \mathrm{mmHg}$, without changes in drug therapy during the preceding 3 months or limitations on physical activity were recruited. Medical history and clinical evaluation were used to exclude persons with cardiovascular, renal, or pulmonary problems, diabetes, and chronic physical or psychological disorders. The maximal graded exercise test (Bruce protocol) ${ }^{15}$ was performed to exclude the presence of coronary artery disease and determine the physical exercise workload. Because betablockers can greatly limit exercise-induced heart rate increases, ${ }^{16}$ the maximal exercise test was performed at the same time of day as the exercise session with patients taking their current medication. Subjects participating in regular physical activity (more than once a week) for the last 6 months were also excluded. In all, 104 patients were screened. A total of 50 hypertensive patients (32 women; 21 postmenopausal) were eligible during the screening process and participated in the study. The reasons for ineligibility included uncontrolled office BP (28 patients), changes in drug therapy (5), type 2 diabetes (11 patients), and pre-participation in physical activity programs (10 patients). The demographics and drug regimens of the studied patients are summarized in Table 1 . The results of the maximal exercise tests are displayed in Table 2.

Table 1 - Subjects' characteristics

\begin{tabular}{|c|c|c|c|c|}
\hline \multirow[t]{2}{*}{ Variable } & \multirow[t]{2}{*}{ Men } & \multicolumn{2}{|c|}{ Women } & \multirow[t]{2}{*}{ Total } \\
\hline & & Pre-menopause & Post-menopause & \\
\hline $\mathrm{N}$ & 18 & 11 & 22 & 50 \\
\hline Age (years) & $45.8 \pm 9.8$ & $40.4 \pm 3.7 *$ & $52.3 \pm 3.4$ & $46.5 \pm 8.2$ \\
\hline BMI $\left(\mathrm{kg} / \mathrm{m}^{2}\right)$ & $27.8 \pm 3.8$ & $28.9 \pm 6.5$ & $26.7 \pm 4.2$ & $27.8 \pm 4.7$ \\
\hline Waist circumference $(\mathrm{cm})$ & $91.5 \pm 9.6$ & $90.7 \pm 11.5$ & $88.4 \pm 11.3$ & $90.1 \pm 11.3$ \\
\hline \multicolumn{5}{|l|}{ Office BP (mmHg) } \\
\hline Systolic & $133.4 \pm 7.2$ & $130.5 \pm 8.2$ & $126.4 \pm 10.6$ & $129.6 \pm 9.2$ \\
\hline Diastolic & $86.3 \pm 3.1$ & $85.1 \pm 5.3$ & $82.1 \pm 8.1$ & $85.3 \pm 4.2$ \\
\hline \multicolumn{5}{|l|}{ Medication } \\
\hline Diuretic & $72 \%$ & $54 \%$ & $59 \%$ & $62 \%$ \\
\hline ACEI & $38 \%$ & $27 \%$ & $40 \%$ & $35 \%$ \\
\hline$\beta$-blocker & $33 \%$ & $45 \%$ & $36 \%$ & $38 \%$ \\
\hline $\mathrm{CaCI}$ & & & & $6 \%$ \\
\hline Mono-therapy & $56 \%$ & $63 \%$ & $50 \%$ & $56 \%$ \\
\hline Combination-therapy & $44 \%$ & $37 \%$ & $50 \%$ & $44 \%$ \\
\hline
\end{tabular}

N: number of patients; F: female; M: male; BMI: body mass index; ACEI: angiotensin-converting enzyme inhibitor; CaCI: calcium channel blocker. Mono-therapy: patients receiving single-drug therapy; Combination-therapy: patients receiving multiple-drug therapy. *: significant different from postmenopause women $(\mathrm{p}<0.001)$ 
Table 2 - Maximal exercise testing

\begin{tabular}{lcc}
\hline Variable & Non- $\beta$-blocker & $\beta$-blocker \\
\hline Exercise time (min) & $7.0 \pm 1.9$ & $7.7 \pm 2.0$ \\
METs & $7.3 \pm 1.1$ & $7.8 \pm 1.3$ \\
BP (mmHg) & & \\
Rest & & \\
$\quad$ Systolic & $134.6 \pm 12.8$ & $140.3 \pm 15.2$ \\
$\quad$ Diastolic & $91.5 \pm 9.8$ & $93.3 \pm 9.6$ \\
Peak & & \\
$\quad$ Systolic & $205.0 \pm 25.1$ & $214.0 \pm 26.7$ \\
$\quad$ Diastolic & $102.1 \pm 17.2$ & $106.7 \pm 11.1$ \\
Heart Rate (bpm) & & \\
$\quad$ Rest & $72.2 \pm 7.7$ & $70.7 \pm 9.5$ \\
$\quad$ Peak & $159.7 \pm 16.2$ & $160.2 \pm 9.0$ \\
\hline
\end{tabular}

Non- $\beta$-blocker: patients do not receiving $\beta$-blocker therapy; $\beta$-blocker: patients receiving $\beta$-blocker therapy. BP: blood pressure.

\section{4-h ambulatory blood pressure monitoring}

The $24 \mathrm{~h} \mathrm{ABP}$ monitoring was performed after an exercise session (post-exercise) and after a nonexercise control period (50 minutes of rest in the sitting position) in random order using a Spacelabs model 90207 ABP monitor (Spacelabs Medical Inc., Redmond, WA). Both control and post-exercise 24-h ABP monitoring began at the same time of day (between 6 and 7 p.m.) and were separated by 2 to 7 days. All recordings were started on a weekday other than Friday.

Subjects were instructed to perform their habitual daily activities, not to engage in formal physical activity, and to relax and straighten the arm during the recording interval for daytime ABP monitoring. Subjects were also asked to document their hours of sleep, time at work, time at leisure activities, and time of medication. The monitor was programmed to measure BP every 15 minutes during the daytime and every 20 minutes during nighttime periods. The daytime and nighttime periods were based on the time patients got into and out of bed.

Individual BP measurements were reviewed for missing and erroneous values. Readings were purged if data were missing, systolic BP was lower than diastolic BP, systolic BP was $>240 \mathrm{mmHg}$ or $<50 \mathrm{mmHg}$, or diastolic BP was $>140 \mathrm{mmHg}$ or $<40 \mathrm{mmHg}$. System-tagged data were purged if systolic BP deviated by more than $\pm 50 \mathrm{mmHg}$ or diastolic BP deviated by more than $\pm 20 \mathrm{mmHg}$ from surrounding values. An average of $89.2 \pm 3.1$ measurements was taken during each $\mathrm{ABP}$ monitoring session; $87.8 \pm 9.5 \%$ of measurements were then analyzed.

For analysis, 24-h ABP monitoring data were classified by 24 -h, daytime, and nighttime periods for systolic, diastolic, and mean BP.

\section{Exercise}

The exercise session took place in the evening (5 to 6 p.m.) and consisted of 40 minutes of aerobic exercise on a cycle-ergometer and 5 minutes of warm-up and cool-down. Exercise intensity was determined according to the workload reached during the maximal graded exercise test and was set at $60 \%$ of the reserve heart rate. The reserve heart rate was calculated by taking the difference between the peak and resting heart rates, then multiplying this number by the intensity of exercise, and adding it to the resting heart rate, according to the Karvonen method. ${ }^{17}$ Peak and resting heart rates were obtained through the graded exercise test. Heart rates were monitored during all exercise sessions using a heart rate monitor (Polar Beat, Polar Electro Inc., Finland).

\section{Statistical methods}

ANOVA was used to compare subject demographics between men and pre- and post-menopause women. Paired $t$-test was used to compare ABP monitoring data. Wilcoxon signed rank test was used to compare the percentage of patients with normal ABP monitoring data between control and post-exercise ABP measurements $(24 \mathrm{~h} \mathrm{BP}<130 / 80$ $\mathrm{mmHg}$, daytime $\mathrm{BP}<135 / 85 \mathrm{mmHg}$, and nighttime $\mathrm{BP}<$ $120 / 70 \mathrm{mmHg}){ }^{18}$ Data are presented as the mean \pm standard deviation. The level of significance was set at $p \leq 0.05$. SPSS 13.0 software was used to perform statistical analyses.

\section{RESULTS}

Because there were more women than men and more post- than pre-menopause women, we first compared the results based on sex and menopause status. However, ANOVA did not detect any effects of sex and menopause status for any measure. Thus, the results were not grouped by sex or menopause status.

Despite the fact that all patients were receiving antihypertensive therapy and office BP was $<140 / 90 \mathrm{~mm}$ $\mathrm{Hg}$, only 14 patients showed normal control ABP levels for all reading periods. The prevalence of masked hypertension (office $\mathrm{BP}<140 / 90 \mathrm{mmHg}$ but daytime $\mathrm{ABP} \geq 135 / 85$ $\mathrm{mmHg})^{18}$ was $52 \%$ and similar to the $48 \%$ observed for high nighttime ABP levels (Table 3).

Exercise was beneficial to ABP, as seen in Figure 1. Statically significant post-exercise decreases were observed 
Table 3 - Prevalence of normal ambulatory blood pressure

\begin{tabular}{llc}
\hline Reading period & $\mathrm{N}$ & Percentage \\
\hline 24-hour & 16 & $32 \%$ \\
Daytime & 24 & $48 \%$ \\
Nighttime & 26 & $52 \%$ \\
All Periods & 14 & $28 \%$ \\
\hline
\end{tabular}

Normal ABP: $<130 / 80 \mathrm{mmHg}$ for $24-\mathrm{h} ;<135 / 85 \mathrm{mmHg}$ for daytime; and $<120 / 70$ for nighttime.

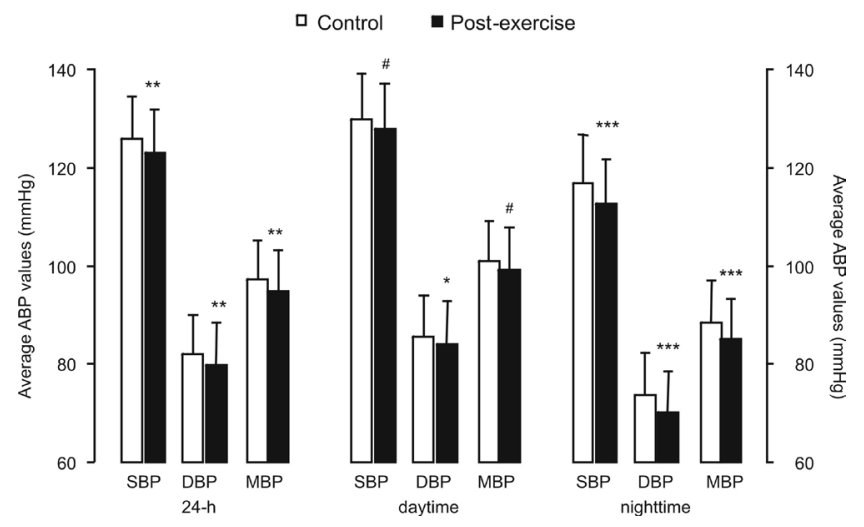

Figure 1 - Average twenty-four hour (24 h), daytime, and nighttime ABP values after a single exercise session (post-exercise) or a nonexercise control period (control). SBP: systolic BP; DBP: diastolic BP; MBP: mean BP. Asterisks denote a significant difference from control period $(* \mathrm{p}=0.04 ; * * \mathrm{p} \leq 0.004$; $* * * \mathrm{p} \leq 0.0001)$. ${ }^{\#}$ Tended to be different from control period $(\mathrm{p}=0.06)$

in systolic, diastolic, and mean 24-h ABP; diastolic daytime ABP; and systolic, diastolic, and mean nighttime ABP. Postexercise systolic and mean daytime ABP tended to decrease $(\mathrm{p}=0.06)$.

Figure 2 shows that decreases in post-exercise ABP increased the prevalence of normal $24 \mathrm{~h}$ and daytime systolic $\mathrm{ABP}$, as well as diastolic nighttime ABP. The prevalence of

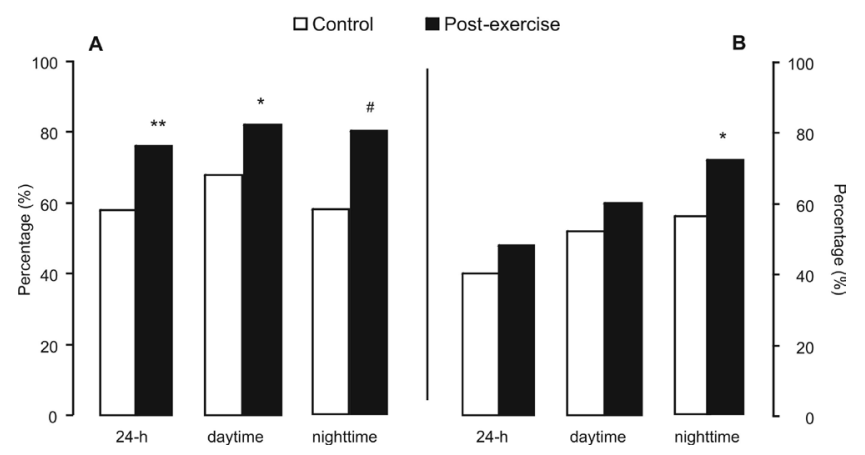

Figure 2 - Percentage of patients with twenty-four hour ( $24 \mathrm{~h}$ ), daytime, and nighttime normal $(<130 / 80 \mathrm{mmHg}$ for $24-\mathrm{h},<135 / 85 \mathrm{mmHg}$ for daytime, and $<120 / 70$ for nighttime) ABP after a single exercise session (post-exercise) or a nonexercise control period (control.). A: systolic blood pressure; B: diastolic blood pressure. Asterisks denote a significant difference from control period $(* \mathrm{p}=0.02 ; * * \mathrm{p}=0.007)$. ${ }^{*}$ Tended to be different from control period $(\mathrm{p}=0.058)$ normal post-exercise $24 \mathrm{~h}$ and daytime diastolic ABP did not increase significantly, but post-exercise systolic nighttime ABP tended to increase $(\mathrm{p}=0.058)$. These post-exercise $\mathrm{BP}$ improvements resulted in a decrease in the prevalence of masked hypertension from $52 \%$ (control) to $28 \%$ (postexercise).

Because the effect of exercise on postexercise ABP reduction is related to the basal $\mathrm{BP}$ level, ${ }^{14}$ we also separately analyzed the effect of exercise on subjects with higher and lower control ABP levels by subdividing them into groups with control ABP above and below the median values (see Table 4). Aerobic exercise only reduced ABP (by 2.6-7.1 $\mathrm{mmHg}$ ) in the subjects with higher control ABP levels (Figure 3).

Table 4 - Median blood pressure values.

\begin{tabular}{lcl}
\hline & SBP & DBP \\
\hline 24-hour & 127.5 & 81.5 \\
Daytime & 132.0 & 84.5 \\
Nighttime & 116.5 & 73.5 \\
\hline
\end{tabular}

SBP: systolic blood pressure; DMP: diastolic blood pressure; MBP: mean blood pressure.

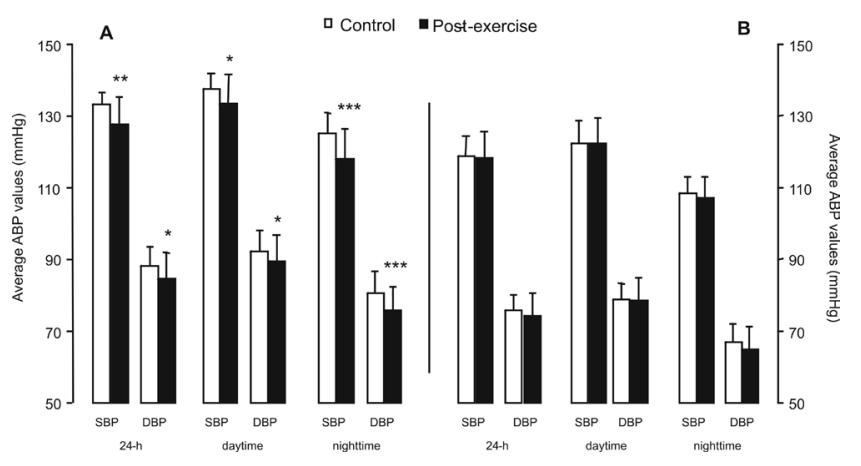

Figure 3 - Average twenty-four hour (24-h), daytime and nighttime ABP values after a single exercise session (post-exercise) or a nonexercise control period (control) for patients with control BP above (A) and below (B) the median value. SBP: systolic BP. DBP: diastolic BP. Asterisks denote a significant difference from control period $(*: \mathrm{p}<0.05 ; * *: \mathrm{p}=0.001$; $* * *$ : $\mathrm{p} \leq 0.0001)$

\section{DISCUSSION}

Exercise has been shown to markedly improve the function of a number of cardiopulmonary parameters ${ }^{19-21}$ and aerobic power. ${ }^{22}$ The primary finding of this research is that a single session of aerobic exercise reduced systolic, diastolic, and mean ABP in sedentary middle-aged longterm-treated hypertensive patients for a substantial portion of the subsequent $24 \mathrm{~h}$ period. This decrease resulted in an increased percentage of patients with normal ABP levels. To 
the best of our knowledge, this is the first study to evaluate the effects of a single bout of aerobic exercise on ABP in long-term-treated hypertensive patients who did not have a washout period before the start of the study.

Post-exercise BP reduction occurs in normotensive and untreated hypertensive, young, middle-aged, and older men and women. ${ }^{12-14,23}$ However, when BP is measured by $\mathrm{ABP}$ monitoring, post-exercise $\mathrm{ABP}$ reduction is only significant in untreated hypertensive and prehypertensive subjects; normotensive subjects showed no difference. . $^{12,14,24}$ The present observations that only subjects with higher control ABP levels showed substantial decreases of systolic, diastolic, and mean $\mathrm{ABP}$ are consistent with these previous findings; however, the basal BP levels of treated hypertensive patients in this study were lower than the BP levels of untreated hypertensive in previous studies. ${ }^{11-13,25}$

The average ABP reduction observed after exercise was similar to the post-exercise ABP reduction described in several other studies ${ }^{13,25}$ but greater than that observed in other studies where no ABP reduction was found. ${ }^{11,26}$ These discrepancies may be caused by different intensities of the exercise performed. In studies where no post-exercise $\mathrm{ABP}$ reductions were found, exercise was of either $\mathrm{low}^{18}$ or maximal intensity. ${ }^{26}$ Low-intensity aerobic exercise yields smaller and shorter-lasting ABP reductions than moderateintensity aerobic exercise. ${ }^{24}$ It is thus possible that lowintensity aerobic exercise is not sufficient to sustain postexercise ABP reduction long enough to be detected by ABP monitoring. On the other hand, maximal exercise results in markedly different hemodynamic, hormonal, and neural responses than submaximal exercise; therefore, it is possible that a lack of sustained ABP reduction after maximal exercise ${ }^{26}$ may be the result of the exercise intensity.

Although the population we studied consisted of hypertensive patients who were responsive to pharmacological treatment (office BP $<140 / 90 \mathrm{mmHg}$ ), there was a high prevalence of masked hypertension $(52 \%)$. Because the prevalence of masked hypertension in treated hypertensive patients has been shown to range from 7 to $20 \%,{ }^{18,27}$ the hypertension treatments in the present study could be interpreted as ineffective. However, when only hypertensive patients responsive to treatment are analyzed, the prevalence of masked hypertension has been shown to range from 27 to $55 \%,{ }^{28}$ similar to the $52 \%$ observed in the present study.

In the present study, the percentage of subjects with normal ABP levels increased for all measurement periods after exercise. With this increase, $72 \%$ and $68 \%$ of patients reached normal daytime and nighttime normal ABP levels, respectively; this improvement represents a masked hypertension prevalence of $28 \%$ after exercise. These results show that aerobic exercise could facilitate antihypertensive treatment and, thus, improve patient prognoses.

Another important point of our study is the interval period between experimental protocols (exercise vs. nonexercise). Because this interval varied from 2 to 7 days, one could argue that patients who exercised first and then underwent the nonexercise session after 48 hours may still showing post-exercise effects during nonexercise $24 \mathrm{~h}$ ABP monitoring. However, previous studies have shown that although post-exercise hypotension may persist for up to 22 hours after exercise bout, it is usually not observed beyond the first 12 h. ${ }^{14}$ Nonexercise measurements of patients who exercised first and then underwent the nonexercise session after 48 hours were therefore probably unaffected by earlier exercise session.

The exact mechanism for the post-exercise hypertension observed in the present study remains unclear but is most likely multifactorial. Acute decreases in BP by physical exercise may be related to reduced peripheral resistance rather than cardiac output, with the exception of older hypertensive subjects. Two mechanisms have been proposed to explain this decrease in peripheral resistance: sympathetic inhibition and altered vascular responsiveness after exercise. ${ }^{14}$ Reduced sympathetic outflow after exercise has been reported in humans, ${ }^{29,30}$ but the mechanisms are unclear. Resetting the operating point of the arterial baroreflex to lower $\mathrm{BP},{ }^{30}$ augmented $\mathrm{GABA}_{\mathrm{A}}$ signaling in the rostral ventrolateral medulla, ${ }^{31}$ and substance $\mathrm{P}$ receptors ${ }^{32}$ in the nucleus tractus solitarius as well as central vasopressin $\mathrm{V}_{1}$ receptors ${ }^{33}$ have all been shown to contribute to reduced sympathetic outflow after exercise session and, thus, may have contributed to the acute post-exercise BP reduction observed in the present study. Blunted vascular responsiveness to $\alpha$-adrenergic stimulation, ${ }^{30,34}$ as well as increased local release of nitric oxide, prostaglandins, adenosine, and ATP, ${ }^{30,35}$ are also factors associated with changes in vascular responsiveness after acute exercise and may have also contributed to the post-exercise $\mathrm{BP}$ reduction observed in this study.

The main limitation of our study is that, although their BP levels were controlled by drug therapy, the subjects were using different quantities and qualities of medication; it is unknown whether different drugs may have influenced the post-exercise ABP reduction. Another limitation is that the exercise test was performed on a motor treadmill, while the exercise session was performed on a cycle-ergometer, as it has been shown that the heart rate response to treadmill exercise testing in sedentary subjects is $10-15 \%$ greater than the heart rate response to cycle-ergometer exercise testing. ${ }^{36}$ Thus, we calculated $60 \%$ of the reserve heart rate on the treadmill and subtracted $10 \%$ to adjust it to the cycleergometer. 
In summary, a single aerobic exercise session reduced ambulatory blood pressure in long-term-treated hypertensive patients and increased the percentage of subjects with normal ambulatory blood pressure levels. These effects suggest that aerobic exercise may be an important tool for blood pressure management of long-term-treated hypertension patients.

\section{ACKNOWLEDGEMENT}

This work was supported by the Fundação de Amparo à Pesquisa do Estado de São Paulo (FAPESP \# 2002/069239).

\section{REFERENCES}

1. Guimarães AC. Hypertension in Brazil. J Hum Hypertens. 2002;16(Suppl 1):S7-S10.

2. Chobanian AV, Bakris GL, Black HR, Cushman WC, Green LA, Izzo JL Jr, et al. The Seventh Report of the Joint National Committee on Prevention, Detection, Evaluation, and Treatment of High Blood Pressure. Hypertension. 2003;42:1206-52.

3. Vasan RS, Larson MG, Leip EP, Evans JC, O’Donnell CJ, Kannel WB, et al. Impact of High-Normal Blood Pressure on the Risk of Cardiovascular Disease. N Engl J Med. 2001;345:1291-97.

4. Zanchetti A, Waeber B. Hypertension: which aspects of hypertension should we impact on and how? J Hypertens. 2006;24(Suppl 5):S2-S5.

5. Julius S, Kjeldsen SE, Weber M, for the VALUE trial group. Outcomes in hypertensive patients at high cardiovascular risk treated with regimens based on valsartan or amlodipine: the VALUE randomized trial. Lancet. 2004;363:2022-31.

6. Niiranen TJ, Kantola IM, Vesalainen R, Johanson J, Ruuska MJ. A comparison of home measurement and ambulatory monitoring of blood pressure in the adjustment of antihypertensive treatment. Am J Hypertens. 2006;19:468-74.

7. Paffenbarger RS Jr., Jung DL, Leun RW, Hyde RT. Physical activity and hypertension: an epidemiological view. Ann Med. 1991; 23:319-27.

8. Haapanen N, Miilunpalo S, Vuori I, Oja P, Pasanen M. Association of leisure time physical activity with the risk of coronary heart disease, hypertension and diabetes in middle-aged men women. Int J Epidemiol. 1997;26:739-47.

9. Hayashi T, Tsumura K, Suematsu C, Okada K, Fujii S, Endo G. Walking to work and the risk for hypertension in men: the Osaka Health Survey. Ann Intern Med. 1999;130:21-6.

10. Whelton SP, Chin A, Xin X, and He J. Effects of aerobic exercise on blood pressure: a meta-analysis of randomized, controlled trials. Ann Intern Med. 2002;136:493-503.

11. Wallace JP, Bogle PG, King BA, Krasnoff JB, Jastremski CA. A comparison of 24-h average blood pressures and blood pressure load following exercise. Am J Hypertens. 1997;10:728-34.

12. Pescatello LS, Miller BMA, Danias PG, Werner M, Hess M, Baker C, et al. Dynamic exercise normalizes resting blood pressure in mildly hypertensive premenopausal women. Am Heart J. 1999;138:916-21.

13. Taylor-Tolbert NS, Dengel DR, Brown MD, McCole SD, Pratley RE, Ferrell RE, et al. Ambulatory blood pressure after acute exercise in older men with essential hypertension. Am J Hypertens. 2001;13:44-51.

14. American College of Sports Medicine. Position Stand: Exercise and Hypertension. Med Sci Sports Exerc. 2004;36:533-53.

15. Bruce RA. Exercise testing of patients with coronary heart disease. Principles and normal standards for evaluation. Ann Clin Res. 1971;3:323-32.

16. Ades PA, Woelfel EE, Hiatt WR, Fee C, Rolfs R, Brammell HL, et al. Exercise hemodynamic effects of beta-blockade and intrinsic sympathomimetic activity. Eur J Clin Pharmacol. 1989;36:5-10.

17. Karvonen M, Kentala K, Mustala O. The effects of training on heart rate: a longitudinal study. Ann Med Exper Biol Fenn. 1957;35:307-15.

18. Alessi A, Brandão AA, Pierin A, Feitosa AM, Machado CA, de Moraes, et al. IV Guideline for Ambulatory Blood Pressure Monitoring - II Guideline for Home Blood Pressure Monitoring. Arq Bras Cardiol. 2005;85 (suppl 2):1-18.
19. Guimarães GV, Carvalho VO, Bocchi EA. Reproducibility of the selfcontrolled six-minute walking test in heart failure patients. Clinics. 2008;63:201-6.

20. Bocalini DS, dos Santos L, Serra AJ. Physical exercise improves the functional capacity and quality of life in patients with heart failure. Clinics. 2008;63:437-42.

21. Carvalho VO, Guimarães GV, Ciolac EG, Bocchi EA. Heart rate dynamics during a treadmill cardiopulmonary exercise test in optimized beta-blocked heart failure patients. Clinics. 2008;63:479-82.

22. Santos-Silva PR, Fonseca AJ, Castro AW, Greve JM, Hernandez AJ. Reproducibility of maximum aerobic power (VO2max) among soccer players using a modified heck protocol. Clinics. 2007;62:391-6.

23. MacDonald JR, MacDougall JD, Hogben CD. The effects of exercise duration on post-exercise hypotension. J Hum Hypertens. 2000;14:1259.

24. Quinn TJ. Twenty-four hour, ambulatory blood pressure responses following acute exercise: impact of exercise intensity. J Hum Hypertens. 2000; $14: 547-53$.

25. Park S, Jastremski CA, Wallace JP. Time of day for exercise on blood pressure reduction in dipping and nondipping hypertension. J Hum Hypertens. 2005;19:597-605.

26. Somers VK, Conway J, Coats A, Isea J, Sleight P. Postexercise hypotension is not sustained in normal and hypertensive subjects. Hypertension. 1991;18:211-5.

27. Pierdomenico SD. The odyssey of masked hypertension in the HOMERUS trial. Am J Hypertens. 2007;20:1266-7.

28. Pierdomenico SD, Cuccurullo F, Mezzetti A. Masked hypertension in treated hypertensive patients. Am J Hypertens. 2006;19:873-4.

29. Floras, J S, Sinkey CA, Aylard PE, Seals DR, Thoren PN, Mark AL. Postexercise hypotension and sympathoinhibition in borderline hypertensive men. Hypertens. 1989;14:28-35.

30. Halliwill JR, Taylor JA, Eckberg DL. Impaired sympathetic vascular regulation in humans after acute dynamic exercise. J Physiol. 1996;495(Pt. 1):279-88.

31. Kajekar R, Chen CY, Mutoh T, Bonham AC. Gaba(a) receptor activation at medullary sympathetic neurons contributes to postexercise hypotension. Am J Physiol Heart Circ Physiol. 2002;282:H1615-24.

32. Chen CY, Munch PA, Quail AW, Bonham AC. Postexercise hypotension in conscious SHR is attenuated by blockade of substance P receptors in NTS. Am J Physiol Heart Circ Physiol. 2002;283:H1856-62.

33. Collins HL, Rodenbaugh DW, Dicarlo SE. Central blockade of vasopressin $\mathrm{V}(1)$ receptors attenuates postexercise hypotension. Am J Physiol. Regul Integr Comp Physiol. 2001;281:R375-80.

34. Patil RD, Dicarlo SE, Collins HL. Acute exercise enhances nitric oxide modulation of vascular response to phenylephrine. Am J Physiol. 1993;265: H1184-8.

35. Rao SP, Collins HL, Dicarlo SE. Postexercise alpha-adrenergic receptor hyporesponsiveness in hypertensive rats is due to nitric oxide. Am J Physiol Regul Integr Comp Physiol. 2002;282:R960-8.

36. Bunc V, Heller J. Exercise intensity conversion from a bicycle ergometer to a treadmill. J Sports Med Phys Fitness. 1991;31:490-3. 